\title{
KAJIAN BANGUNAN WISATA DALAM MENDUKUNG CITY BRANDING DI KOTA CIREBON \\ (Studi Kasus: Masjid Sang Cipta Rasa dan Masjid Merah Panjunan)
}

\author{
(Study of Tourism Building in Supporting City Branding of Cirebon - Case Study: Sang Cipta \\ Rasa Mosque and Panjunan Red Mosque)
}

\author{
Fatin Adriati ${ }^{1}$, Eli Jamilah Mihardja ${ }^{2}$ \\ ${ }^{1}$ Program Studi Teknik Sipil Universitas Bakrie \\ ${ }^{2}$ Program Studi IImu Komunikasi Universitas Bakrie \\ E-mail: adriati04teen@gmail.com
}

\begin{abstract}
ABSTRAK
Obyek wisata yang berupa bangunan wisata dapat "dijual" untuk menunjang pembentukan dan sustainability city branding kota Cirebon. Untuk dapat "dijual", bangunan wisata tersebut harus dalam kondisi yang layak dan memiliki sarana dan prasarana yang memadai. Penelitian ini menggunakan metode pengamatan langsung dan analisis komparatif deskriptif terhadap Masjid Sang Cipta Rasa dan Masjid Merah Panjunan sebagai obyek penelitian dalam menentukan kesiapan sarana dan prasarana bangunan wisata. Fasilitas dan aksesibilitas sebagai sarana bangunan wisata berpedoman pada empat asas yaitu: 1) asas keselamatan; 2) asas kemudahan; 3) asas kegunaan; dan 4) asas kemandirian, sedangkan bangunan wisata sebagai prasarana berpedoman pada lima persyaratan yaitu: 1) persyaratan keselamatan; 2) persyaratan kesehatan; 3) persyaratan kenyamanan; 4) persyaratan kemudahan; dan 5) persyaratan efisiensi, seimbang, serasi dan selaras. Terjaganya sustainability sarana dan prasarana bangunan wisata dapat diwujudkan melalui pemeliharaan bangunan yang dikelompokkan menjadi lima aspek antara lain: 1) arsitektural; 2) struktural; 3) mekanikal; 4) elektrikal; dan 5) tata luar ruang dan house keeping. Berdasarkan hasil penelitian, sarana dan prasarana Masjid Sang Cipta Rasa dan Masjid Merah Panjunan belum memadai dan belum optimal, terutama pada aspek keselamatan dan kebersihan. Oleh karena itu, perlu upaya yang lebih sinergis dari semua pemangku kepentingan dalam pemeliharaan kota sehingga bangunan bersejarah sebagai potensi pariwisata dalam menunjang pembentukan city branding dapat dioptimalkan.
\end{abstract}

Kata Kunci: aksesibilitas, city branding, bangunan wisata, fasilitas, kota Cirebon

\begin{abstract}
Tourism building could be "sold" in order to support establishment and sustainability of city branding of Cirebon city. To be "sold", tourism building must be in decent condition and has sufficient facilities and infrastructure. This research used direct observation and descriptive comparative analysis of Masjid Sang Cipta Rasa and Masjid Merah Panjunan as research object, to determine the readiness of its facilities and infrastructure. Facilities and accessibility of tourism building should follows four principles, namely: 1) safety; 2) convenience; 3) utility; and 4) independence, meanwhile the infrastructure should follows five requirements, namely: 1) safety; 2) health; 3) comfort; 4) convenience; and 5) efficiency, balanced and harmonious. Maintaining the sustainability of facilities and infrastructure of tourism building could be realized through the maintenance of building which grouped into five aspect, namely: 1) architectural; 2) structural; 3) mechanical; 4) electrical; and 5) outdoor layout and house keeping. Based on the result of the research, the facilities and infrastructure of Masjid Sang Cipta Rasa dan Masjid Merah Panjunan are insufficient and not optimized yet, especially in safety and sanitation. Therefore, it is necessary for more synergistic efforts from the stakeholders so as historical buildings as tourism potential could be optimized in order to support city branding.
\end{abstract}

Keywords:accessibility, city branding, Cirebon city, facilities, tourism building 


\section{PENDAHULUAN}

Hampir setiap kota di seluruh dunia mulai berbenah diri untuk dapat bersaing dalam persaingan global, salah satunya dalam sektor pariwisata. Begitu juga kota-kota di Indonesia, termasuk kota Cirebon, yang bermodal dasar kekayaan potensi alam dan budaya sedang berupaya untuk mengembangkan potensipotensi tersebut dengan menggunakan konsep city branding (Jannah dkk, 2014). Pengertian city branding sendiri merupakan upaya untuk memberikan merek kepada kota agar mudah dikenali, meningkatkan daya saing dan dapat membentuk city image untuk memasarkan daerah baik secara lokal maupun internasional (Jannah dkk, 2014; Sukmaraga \& Nirwana, 2016). Dengan adanya branding pada suatu kota akan berdampak pada sumber daya, perhatian dan kunjungan wisatawan, baik domestik maupun mancanegara, serta investasi yang semakin meningkat dan pada akhirnya memutar roda perekonomian di kota tersebut (Kavaratzis \& Ashwort, 2006; Jannah dkk, 2014; Karim dkk, 2014; Romandhona, 2016).

Dalam penentuan branding suatu kota hendaknya didasarkan pada karakteristik kota itu sendiri (Widodo \& Setiansah, 2014). Segala sesuatu yang dikandung oleh suatu kota, segala sesuatu yang bertempat di suatu kota atau segala sesuatu yang dilakukan oleh kota dapat menjadi cikal bakal branding kota tersebut (Karim dkk, 2014). Menurut Dinnie (2011, dalam Susilo, 2011), kota Cirebon memiliki beberapa karakteristik yang dapat dipertimbangkan sebagai tema city branding diantaranya (1) kota transit untuk perdagangan, (2) kota yang memiliki peninggalan budaya bermakna tinggi (3) kota berbudaya majemuk dengan berbagai ragam kesenian, (4) kota yang memiliki berbagai ragam kuliner lezat, dan (5) kota dengan corak batik khas karangan dan mega mendung.

Penentuan branding suatu kota tidak akan membuahkan hasil jika hanya berkutat pada karakteristik kota dan tidak didukung oleh sinergi dari keseluruhan unsur pembentuk kota, baik dari aspek sumber daya manusia, sarana dan prasarana yang memadai, fasilitas umum (akomodasi, travel agent, tourism information center, pusat medis dan kesehatan), fasilitas sosial maupun sistem transportasi (Karim dkk, 2014; Romandhona, 2016). Dari tiga tahapan komunikasi dalam membangun city branding menurut Kavaratzis (2004: 66), tahapan primer secara jelas mendukung pernyataan bahwa memang diperlukan sinergi dari keseluruhan unsur pembentuk kota. Pada tahapan primer (primary communication), citra kota sangat terkait dengan pengelolaan ruang/landscape strategies (desain, arsitektur, ruang publik, dan pertunjukan seni), perilaku/behavior (kualitas pelayanan, peristiwa, insentif finansial, dan peluang yang tersedia), infrastruktur/infrastructure (aksesibilitas, fasilitas budaya dan pariwisata) serta struktur organisasi/organizational structure (budaya internal, komunitas lokal, sinergi, dan partisipasi warga kota). Berdasarkan pendapat dan penjelasan tersebut, maka dapat dikatakan bahwa salah satu unsur pembentuk kota yang harus dikelola adalah bangunan wisata dan infrastrukturnya.

Pengembangan bangunan wisata dan infrastrukturnya akan meningkatkan kemampuan kota dalam menarik pengunjung (Wibawanto, 2015). Kota Cirebon yang dikatakan sebagai kota dengan peninggalan budaya bermakna tinggi, memiliki beberapa bangunan bersejarah yang dapat dijadikan obyek wisata (Nursinggih, 2011), diantaranya Keraton Kanoman, Keraton Kasepuhan, Keraton Kacirebonan, Masjid Sang Cipta Rasa, Masjid Merah Panjunan, dan British American Tobacco (BAT). Obyek wisata berupa bangunan wisata inilah yang dapat "dijual" untuk menunjang pembentukan dan sustainability dari city branding kota Cirebon. Tentu saja untuk dapat "dijual", bangunan-bangunan wisata tersebut harus dalam kondisi yang layak dan memiliki sarana dan prasarana yang memadai dan optimal. Berdasarkan hal tersebut, penelitian ini dilakukan untuk mengkaji bangunan wisata yang ada di kota Cirebon khususnya kesiapan sarana dan prasarananya dari sudut pandang bidang teknik Sipil.

\section{METODOLOGI}

Penelitian dilakukan di kota Cirebon, salah satu kota di Provinsi Jawa Barat, yang juga menerapkan konsep city branding untuk mempromosikan diri. Pemilihan kota Cirebon sebagai lokasi penelitian selain karena memiliki beberapa "obyek yang bisa dijual" berupa bangunan wisata, sebagai pendukung city branding, juga dikarenakan kota Cirebon dianggap masih kurang dalam menyiapkan "obyek yang akan dijual" tersebut yang bisa diartikan sebagai kesiapan sarana dan prasarana bangunan wisata. Obyek penelitian difokuskan pada dua bangunan wisata yaitu: (1) Masjid Sang Cipta Rasa (Gambar 1), dan (2) Masjid Merah Panjunan (Gambar 2). Masjid Sang Cipta Rasa merupakan masjid peninggalan Wali Songo dengan keunikan berupa ketiadaan menara masjid dan memiliki gaya arsitektur tersendiri. Begitu juga Masjid Merah Panjunan dengan ukuran yang lebih kecil. Penelitian dilakukan dalam dua tahap yaitu kajian pustaka dan studi lapangan. Kajian pustaka dilakukan dalam rentang waktu antara September 2017 hingga Maret 2018, sedangkan studi lapangan dilakukan pada Februari 2018.

Sarana dan prasarana dari bangunan wisata menjadi variabel yang diteliti dalam penelitian ini. Data diperoleh dengan melakukan pengamatan langsung (di Masjid Sang Cipta Rasa dan Masjid Merah Panjunan) terhadap aspek struktur, arsitektur, mekanikal, dan elektrikal dari bangunan, serta fasilitas dan aksesibilitas. Analisis data dilakukan menggunakan metode analisis komparatif deskriptif yaitu dengan mendeskripsikan dan menjelaskan 
kondisi teraktual dari sarana dan prasarana obyek penelitian. Hasil deskripsi dibandingkan standar peraturan yang berlaku di Indonesia baik tentang bangunan gedung maupun kepariwisataan. Tahap akhir penelitian berupa kajian untuk memperoleh kesimpulan mengenai kesiapan sarana dan prasarana Masjid Sang Cipta Rasa dan Masjid Panjunan sebagai pendukung city branding di kota Cirebon.

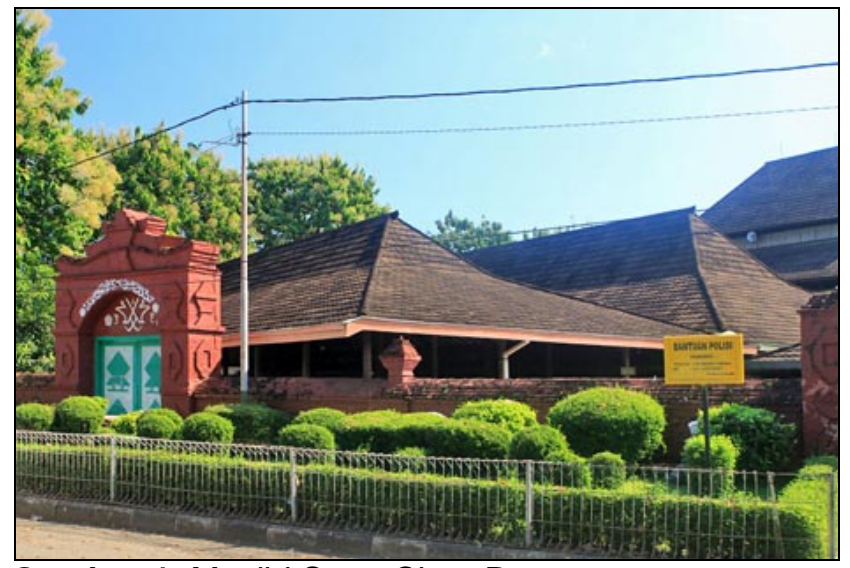

Gambar 1. Masjid Sang Cipta Rasa

Sumber: http://majalahlangitan.com/masjid-agung-sangcipta-rasa-peninggalan-walisongo-di-kota-cirebon/

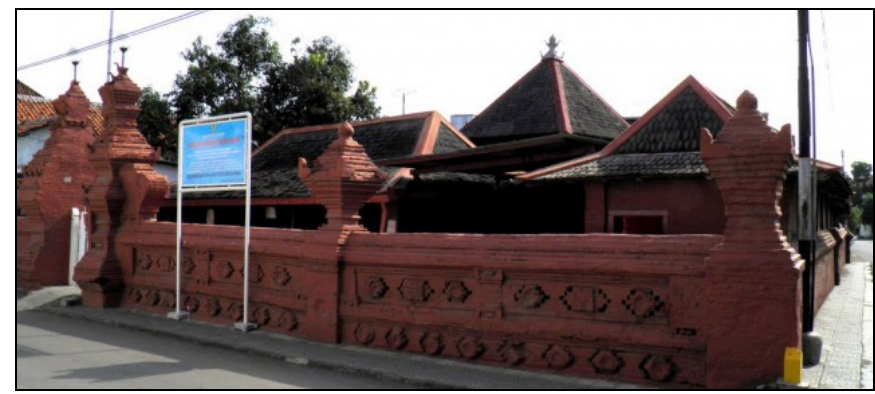

Gambar 2. Masjid Merah Panjunan

Sumber: http://www.nabarentcar.com/city-tour-cirebon-sejarahmasjid-merah-panjunan/

\section{HASIL DAN PEMBAHASAN}

Pembentukan city branding kota Cirebon bisa didasarkan pada sektor pariwisata, yaitu dengan 'menjual' obyek-obyek wisata di kota tersebut, khususnya wisata budaya yang salah satunya berwujud bangunan wisata seperti Masjid Sang Cipta Rasa dan Masjid Merah Panjunan. Dalam mendukung pembentukan dan sustainbability dari city branding dengan konsep pariwisata, maka perlu untuk menyiapkan bangunan wisata "yang akan dijual". Selain untuk kepentingan city branding, persiapan bangunan wisata juga bertujuan agar menghasilkan pariwisata yang memadai dan berkelanjutan. Pernyataan sebelumnya ini sesuai dengan Pasal 3 PERMEN Pariwisata RI No.14 Tahun 2016 tentang Pedoman Destinasi Pariwisata Berkelanjutan, dimana diperlukan pengelolaan, perlindungan, pemanfaatan, dan pengembangan kawasan sebagai destinasi pariwisata yang berkelanjutan.
Persiapan bangunan wisata "yang akan dijual" difokuskan pada sarana dan prasarananya. Sarana dapat diartikan sebagai fasilitas dan aksesibilitas bangunan wisata, sedangkan prasarana dapat diartikan sebagai bangunan wisata itu sendiri.

\section{- Sarana Bangunan Wisata}

Sama seperti bangunan pada umumnya, bangunan wisata juga harus dilengkapi dan didukung oleh fasilitas dan aksesibilitas yang memadai. Hal ini sesuai dengan Pasal 3 ayat (1) PERMEN PU No.30/PRT/M/2006 tentang Pedoman Teknis Fasilitas dan Aksesibilitas pada Bangunan Gedung dan Lingkungan, bahwa dalam merencanakan, dan melaksanakan pembangunan bangunan dan lingkungan harus dilengkapi dengan penyediaan fasilitas dan aksesibilitas. Masjid Sang Cipta Rasa dan Masjid Merah Panjunan selain memiliki fungsi keagamaan, juga memiliki fungsi sosial dan budaya (bangunan kebudayaan) dengan kondisi bangunan yang sudah ada. Bangunan yang sudah ada tetap diwajibkan untuk memenuhi pedoman teknis fasilitas dan aksesibilitas yang telah diatur oleh pemerintah. Meskipun demikian, dalam pemenuhan fasilitas dan aksesibilitas, Masjid Sang Cipta Rasa dan Masjid Merah Panjunan sebagai bangunan bersejarah, juga diwajibkan untuk mengikuti pedoman standar teknis pelestarian budaya yang berlaku.

Fasilitas dan aksesibilitas selain harus ada pada bangunan wisata, juga harus didasarkan pada empat asas, sebagai berikut:

a. Asas Keselamatan

Bangunan harus memperhatikan keselamatan semua orang

b. Asas Kemudahan

Bangunan harus dapat dicapai dan dijangkau semua orang

c. Asas Kegunaan

Bangunan harus dapat dipergunakan oleh semua orang, terutama bangunan yang bersifat umum

d. Asas Kemandirian

Bangunan harus dapat dicapai, dijangkau, dimasuki dan dipergunakan oleh semua orang tanpa memerlukan bantuan orang lain

Berpedoman pada keempat asas tersebut, pada Tabel 1 disajikan referensi fasilitas dan aksesibilitas yang minimal harus ada pada bangunan wisata.

Tabel 1. Referensi Fasilitas dan Aksesibilitas pada Bangunan Wisata

\begin{tabular}{|c|l|l|}
\hline No. & \multicolumn{1}{|c|}{ Asas Keselamatan } & \multicolumn{1}{|c|}{ Asas Kemudahan } \\
\hline 1 & Pos Keamanan & Pintu \\
\hline 2 & Perlengkapan P3K & Tangga \\
\hline 3 & $\begin{array}{l}\text { APAR (alat pemadam } \\
\text { api ringan) }\end{array}$ & $\begin{array}{l}\text { Rambu dan Marka } \\
\text { (penunjuk arah, nama } \\
\text { fasilitas dan tempat) }\end{array}$ \\
\hline 4 & $\begin{array}{l}\text { Petunjuk Keselamatan } \\
\text { (di titik-titik strategis) }\end{array}$ & $\begin{array}{l}\text { Petunjuk arah menuju } \\
\text { lokasi P3K }\end{array}$ \\
\hline
\end{tabular}




\begin{tabular}{|c|c|c|}
\hline No. & Asas Keselamatan & Asas Kemudahan \\
\hline 5 & $\begin{array}{l}\text { Sistem Deteksi \& Alarm } \\
\text { Kebakaran }\end{array}$ & Jalur Pedestrian \\
\hline 6 & $\begin{array}{l}\text { Sistem Komunikasi } \\
\text { (sistem telepon, sistem } \\
\text { tata suara, sistem voice } \\
\text { evacuation) }\end{array}$ & Jalur Pemandu \\
\hline 7 & $\begin{array}{l}\text { Sistem Peringatan } \\
\text { Bahaya }\end{array}$ & \\
\hline 8 & $\begin{array}{l}\text { Sistem Pompa } \\
\text { Kebakaran }\end{array}$ & \\
\hline 9 & $\begin{array}{l}\text { Akses Evakuasi (exit, } \\
\text { tanda arah keluar, } \\
\text { penerangan/pencahaya } \\
\text { an darurat, fan } \\
\text { presurisasi, tangga } \\
\text { kebakaran) }\end{array}$ & \\
\hline No. & Asas Kegunaan & Asas Kemandirian \\
\hline 1 & Toilet Umum & Ram \\
\hline 2 & $\begin{array}{l}\text { Telepon Umum/Fasilitas } \\
\text { Komunikasi }\end{array}$ & $\begin{array}{l}\text { Lift bagi Penyandang } \\
\text { Cacat \& Lansia }\end{array}$ \\
\hline 3 & Ruang Ibadah & $\begin{array}{l}\text { Area parkir bagi } \\
\text { Penyandang Cacat }\end{array}$ \\
\hline 4 & Ruang Ganti & $\begin{array}{l}\text { Akses menuju } \\
\text { Transportasi Umum }\end{array}$ \\
\hline 5 & Ruang Bayi & \\
\hline 6 & Tempat Sampah & \\
\hline 7 & ATM & \\
\hline 8 & Fasilitas Informasi & \\
\hline 9 & Area Parkir Umum & \\
\hline
\end{tabular}

Sumber: adaptasi dari PERMEN PU No.30/PRT/M/20

\section{- Prasarana Bangunan Wisata}

Berdasarkan fungsinya, Masjid Sang Cipta Rasa dan Masjid Merah Panjunan dikelompokkan sebagai bangunan peribadatan dan bangunan budaya (PERMEN PU No.29/PRT/M/2006 tentang Pedoman Persyaratan Teknis Bangunan Gedung). Karena merupakan bangunan budaya, kedua bangunan tersebut juga bisa dikelompokkan sebagai bangunan wisata. Terlepas dari pengelompokkan tersebut, Masjid Sang Cipta Rasa dan Masjid Merah Panjunan harus memenuhi persyaratan administratif dan persyaratan teknik yang meliputi persyaratan tata dan keandalan bangunan, yang diatur dalam Pasal 7 UU No.28 Tahun 2002 tentang Bangunan Gedung. Persyaratan keandalan bangunan didasarkan pada empat kategori (UU No.28 Tahun 2002, PP No.36 tahun 2005 tentang Peraturan Pelaksanaan UU No.28 Tahun 2002, PERMEN PU No.29/PRT/M/2006 tentang Pedoman Persyaratan Teknis Bangunan Gedung) yaitu:

\section{a. Persyaratan Keselamatan}

Menjamin keselamatan manusia dari kemungkinan kecelakaan atau luka yang disebabkan oleh kegagalan struktur bangunan, bahaya kebakaran, bahaya petir, dan bahaya kelistrikan

b. Persyaratan Kesehatan

Menjamin kebutuhan udara, pencahayaan, dan sarana sanitasi

c. Persyaratan Kenyamanan

Menjamin kenyamanan dari gangguan suara dan getaran

\section{d. Persyaratan Kemudahan}

Menjamin akses yang layak dan berfasilitas, pertandaan, jalur evakuasi

e.Persyaratan efisien, seimbang, serasi dan selaras dengan lingkungan bangunan

Berpedoman pada persyaratan-persyaratan di atas, pada Tabel 2 disajikan referensi keandalan minimal yang harus dimiliki bangunan wisata.

Tabel 2. Referensi Keandalan Bangunan Wisata

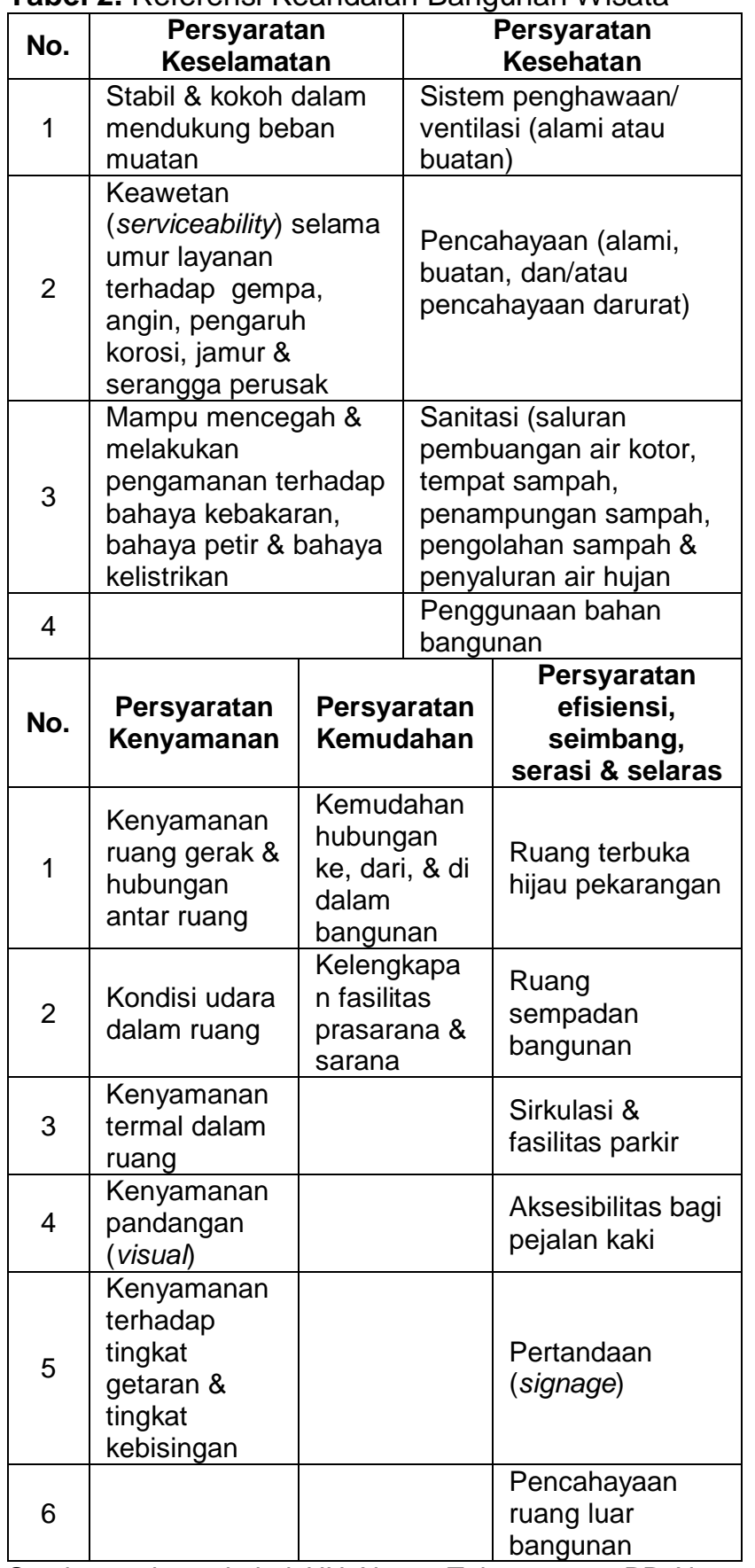

Sumber: adaptasi dari UU No.28 Tahun 2002, PP No.36 tahun 2005 dan PERMEN PU No.29/PRT/M/2006

\section{- Pemeliharaan Bangunan Wisata}

Apabila sarana dan prasarana sudah memadai yang menandakan bahwa bangunan wisata sudah siap "dijual", maka langkah berikutnya adalah membuat 
bangunan wisata tersebut untuk "terus terjual". Bangunan wisata yang "terus terjual" merupakan bangunan wisata yang terjaga sustainability sarana dan prasarananya. Terjaganya sustainability sarana dan prasarana bangunan wisata dapat diwujudkan melalui pemeliharaan bangunan. Pemeliharaan bangunan secara baik, konsisten dan teratur merupakan persyaratan yang harus dipenuhi bagi setiap bangunan (Adriansyah, 2014). Pemeliharaan bangunan adalah kegiatan menjaga keandalan bangunan gedung secara baik dan teratur beserta prasarana dan sarananya agar bangunan selalu laik fungsi (PERMEN PU No.24 Tahun 2008 tentang Pedoman Pemeliharaan dan Perawatan Bangunan), termasuk juga di dalamnya pemeliharaan kebersihan yang dilakukan secara periodik dengan metode pembersihan yang disesuaikan dengan apa yang dibersihkan. Pemeliharaan bangunan dikelompokkan menjadi 5 aspek, antara lain:
a. Arsitektura
b. Struktural
c. Mekanikal
Meliputi tata udara, sanitasi, plumbing, dan transportasi dalam gedung
d. Elektrikal
Meliputi catu daya, tata cahaya, komunikasi, dan alarm
e. Tata ruang luar dan house keeping

Pada Tabel 3 disajikan referensi tentang pemeliharaan bangunan wisata.

Tabel 3. Referensi Pemeliharaan Bangunan Wisata

\begin{tabular}{|c|c|c|c|c|}
\hline No. & \multicolumn{2}{|c|}{ Arsitektural } & \multicolumn{2}{|r|}{ Struktural } \\
\hline 1 & \multicolumn{2}{|c|}{$\begin{array}{l}\text { Jalan keluar (sarana } \\
\text { penyelamat/ egress) }\end{array}$} & \multicolumn{2}{|c|}{$\begin{array}{l}\text { Unsur-unsur struktur } \\
\text { bangunan }\end{array}$} \\
\hline 2 & \multicolumn{2}{|c|}{$\begin{array}{l}\text { Unsur-unsur tampak } \\
\text { luar bangunan } \\
\text { meliputi ornamen } \\
\text { arsitektural \& dekorasi }\end{array}$} & \multicolumn{2}{|c|}{$\begin{array}{l}\text { Unsur-unsur pelindung } \\
\text { struktur }\end{array}$} \\
\hline 3 & \multicolumn{2}{|c|}{$\begin{array}{l}\text { Unsur-unsur dalam } \\
\text { ruang \& } \\
\text { perlengkapannya }\end{array}$} & \multicolumn{2}{|c|}{$\begin{array}{l}\text { Pemeriksaan berkala } \\
\text { (preventive maintenance) }\end{array}$} \\
\hline 4 & \multicolumn{2}{|c|}{$\begin{array}{l}\text { Tersedia sistem \& } \\
\text { peralatan } \\
\text { pemeliharaan }\end{array}$} & \multicolumn{2}{|c|}{$\begin{array}{l}\text { Memfungsikan bangunan } \\
\text { sesuai rencana } \\
\text { penggunaan }\end{array}$} \\
\hline 5 & \multicolumn{2}{|c|}{$\begin{array}{l}\text { Tersedia petugas yang } \\
\text { kompeten di bidang } \\
\text { arsitektur }\end{array}$} & \multicolumn{2}{|c|}{$\begin{array}{l}\text { Tersedia petugas yang } \\
\text { kompeten di bidang } \\
\text { struktur }\end{array}$} \\
\hline No. & Mekanikal & \multicolumn{2}{|c|}{ Elektrikal } & $\begin{array}{c}\text { Tata Ruang Luar } \\
\text { \& House } \\
\text { Keeping }\end{array}$ \\
\hline 1 & $\begin{array}{l}\text { Pemeriksaan } \\
\text { berkala } \\
\text { sistem tata } \\
\text { udara }\end{array}$ & $\begin{array}{l}\text { Pemer } \\
\text { periodi } \\
\text { perlen } \\
\text { pemba } \\
\text { daya li } \\
\text { cadan }\end{array}$ & $\begin{array}{l}\text { saan } \\
\text { kapan } \\
\text { gkit } \\
\text { rik } \\
\text { an }\end{array}$ & $\begin{array}{l}\text { Kondisi \& } \\
\text { permukaan } \\
\text { tanah/halaman } \\
\text { luar }\end{array}$ \\
\hline 2 & $\begin{array}{l}\text { Pemeriksaan } \\
\text { berkala } \\
\text { sistem } \\
\text { distribusi air }\end{array}$ & $\begin{array}{l}\text { Pemer } \\
\text { periodi } \\
\text { perlen } \\
\text { penan } \\
\text { petir }\end{array}$ & $\begin{array}{l}\text { saan } \\
\text { xapan } \\
\text { kal }\end{array}$ & $\begin{array}{l}\text { Unsur-unsur } \\
\text { pertamanan di } \\
\text { luar dan di dalam } \\
\text { meliputi } \\
\text { landscape, } \\
\text { hardscape, } \\
\text { landscape }\end{array}$ \\
\hline
\end{tabular}

\begin{tabular}{|c|c|c|c|}
\hline & & & $\begin{array}{l}\text { furniture, saluran } \\
\text { pembuangan, } \\
\text { pagar, pintu } \\
\text { gerbang, lampu } \\
\text { penerangan luar, } \\
\& \text { pos jaga }\end{array}$ \\
\hline 3 & $\begin{array}{l}\text { Pemeriksaan } \\
\text { berkala } \\
\text { sistem } \\
\text { transportasi } \\
\text { dalam } \\
\text { gedung (lift, } \\
\text { eskalator, } \\
\text { travelator, } \\
\text { tangga, \& alat } \\
\text { transportasi } \\
\text { vertikal } \\
\text { lainnya) }\end{array}$ & $\begin{array}{l}\text { Pemeriksaan } \\
\text { periodik } \\
\text { sistem } \\
\text { instalasi } \\
\text { listrik }\end{array}$ & $\begin{array}{l}\text { Kebersihan di } \\
\text { luar, pekarangan } \\
\text { \& lingkungan }\end{array}$ \\
\hline 4 & & $\begin{array}{l}\text { Pemeriksaan } \\
\text { periodik } \\
\text { sistem } \\
\text { instalasi tata } \\
\text { suara dan } \\
\text { komunikasi } \\
\end{array}$ & $\begin{array}{l}\text { Tersedia petugas } \\
\text { yang kompeten di } \\
\text { bidang } \\
\text { pertamanan }\end{array}$ \\
\hline 5 & & $\begin{array}{l}\text { Pemeriksaan } \\
\text { periodik } \\
\text { sistem tanda } \\
\text { bahaya \& } \\
\text { alarm }\end{array}$ & $\begin{array}{l}\text { Cleaning service, } \\
\text { pest control }\end{array}$ \\
\hline
\end{tabular}

Sumber: adaptasi dari PERMEN PU No.24 Tahun 2008

Dengan menggunakan referensi pada Tabel 1-3 sebagai indikator, pada Tabel 4 disajikan checklist untuk menentukan tingkat kesiapan sarana dan prasarana Masjid Sang Cipta Rasa dan Masjid Merah Panjunan.

Tabel 4. Checklist Kesiapan Sarana dan Prasarana Bangunan Wisata

\begin{tabular}{|l|c|c|c|c|}
\hline \multirow{2}{*}{\multicolumn{1}{|c|}{ Indikator }} & \multicolumn{2}{c|}{$\begin{array}{c}\text { Masjid Sang } \\
\text { Cipta Rasa }\end{array}$} & \multicolumn{2}{c|}{$\begin{array}{c}\text { Masjid Merah } \\
\text { Panjunan }\end{array}$} \\
\cline { 2 - 5 } & Ada & Tidak & Ada & Tidak \\
\hline Pos keamanan & & $\mathrm{v}$ & & $\mathrm{v}$ \\
\hline Toilet umum & $\mathrm{v}$ & & $\mathrm{v}$ & \\
\hline Perlengkapan P3K & & $\mathrm{v}$ & & $\mathrm{v}$ \\
\hline APAR & $\mathrm{v}$ & & $\mathrm{v}$ & \\
\hline $\begin{array}{l}\text { Petunjuk } \\
\text { keselamatan }\end{array}$ & & $\mathrm{v}$ & & $\mathrm{v}$ \\
\hline $\begin{array}{l}\text { Akses menuju } \\
\text { transportasi umum }\end{array}$ & & $\mathrm{v}$ & & $\mathrm{v}$ \\
\hline Jalur pedestrian & $\mathrm{v}$ & & $\mathrm{v}$ & \\
\hline Tempat sampah & $\mathrm{v}$ & & $\mathrm{v}$ & \\
\hline Akses evakuasi & & $\mathrm{v}$ & & $\mathrm{v}$ \\
\hline Kekuatan struktur & $\mathrm{v}$ & & $\mathrm{v}$ & \\
\hline $\begin{array}{l}\text { Kenyamanan ruang } \\
\text { gerak \& hubungan } \\
\text { antar ruang }\end{array}$ & $\mathrm{v}$ & & $\mathrm{v}$ & \\
\hline $\begin{array}{l}\text { Ruang terbuka } \\
\text { hijau }\end{array}$ & & $\mathrm{v}$ & & $\mathrm{v}$ \\
\hline Pencahayaan & $\mathrm{v}$ & & $\mathrm{v}$ & \\
\hline $\begin{array}{l}\text { Ruang sempadan } \\
\text { bangunan }\end{array}$ & & $\mathrm{v}$ & & $\mathrm{v}$ \\
\hline $\begin{array}{l}\text { Kenyamanan } \\
\text { termal dalam ruang }\end{array}$ & $\mathrm{v}$ & & $\mathrm{v}$ & \\
\hline $\begin{array}{l}\text { Kenyamanan } \\
\text { terhadap getaran \& } \\
\text { kebisingan }\end{array}$ & & $\mathrm{v}$ & & $\mathrm{v}$ \\
\hline
\end{tabular}




\begin{tabular}{|c|c|c|c|c|}
\hline Daya listrik & $\mathrm{v}$ & & $\mathrm{V}$ & \\
\hline $\begin{array}{l}\text { Landscape \& } \\
\text { Hardscape }\end{array}$ & & v & & $\mathrm{v}$ \\
\hline Kebersihan & & $\mathrm{v}$ & & $\mathrm{v}$ \\
\hline Pintu & $\mathrm{v}$ & & $\mathrm{v}$ & \\
\hline Ram & & v & & V \\
\hline $\begin{array}{l}\text { Fasilitas } \\
\text { komunikasi }\end{array}$ & & v & & V \\
\hline $\begin{array}{l}\text { Rambu \& marka } \\
\text { (signage) }\end{array}$ & & v & & V \\
\hline $\begin{array}{l}\text { Area parkir } \\
\text { (umum \& } \\
\text { penyandang } \\
\text { cacat) }\end{array}$ & & v & & V \\
\hline Ruang ganti & & $\mathrm{V}$ & & $\mathrm{V}$ \\
\hline $\begin{array}{l}\text { Sistem deteksi \& } \\
\text { alarm kebakaran }\end{array}$ & & v & & V \\
\hline Ruang bayi & & $\mathrm{v}$ & & $\mathrm{V}$ \\
\hline $\begin{array}{l}\text { Sistem } \\
\text { peringatan } \\
\text { bahaya }\end{array}$ & & V & & V \\
\hline $\begin{array}{l}\text { Fasilitas } \\
\text { informasi }\end{array}$ & & V & & $\mathrm{v}$ \\
\hline $\begin{array}{l}\text { Sistem } \\
\text { penghawaan }\end{array}$ & $\mathrm{V}$ & & V & \\
\hline $\begin{array}{l}\text { Kemudahan } \\
\text { hubungan ke, } \\
\text { dari, \& di dalam } \\
\text { bangunan }\end{array}$ & V & & & V \\
\hline $\begin{array}{l}\text { Keawetan } \\
\text { (serviceability) }\end{array}$ & $\mathrm{V}$ & & $\mathrm{V}$ & \\
\hline $\begin{array}{l}\text { Kelengkapan } \\
\text { fasilitas }\end{array}$ & & $\mathrm{v}$ & & V \\
\hline Sanitasi & & $\mathrm{v}$ & & $\mathrm{V}$ \\
\hline $\begin{array}{l}\text { Kenyamanan } \\
\text { pandangan }\end{array}$ & $\mathrm{V}$ & & $\mathrm{V}$ & \\
\hline $\begin{array}{l}\text { Pencahayaan } \\
\text { ruang luar } \\
\text { bangunan }\end{array}$ & & $\mathrm{v}$ & & $\mathrm{v}$ \\
\hline $\begin{array}{l}\text { Unsur tampak } \\
\text { luar bangunan }\end{array}$ & & $\mathrm{v}$ & & $\mathrm{v}$ \\
\hline
\end{tabular}

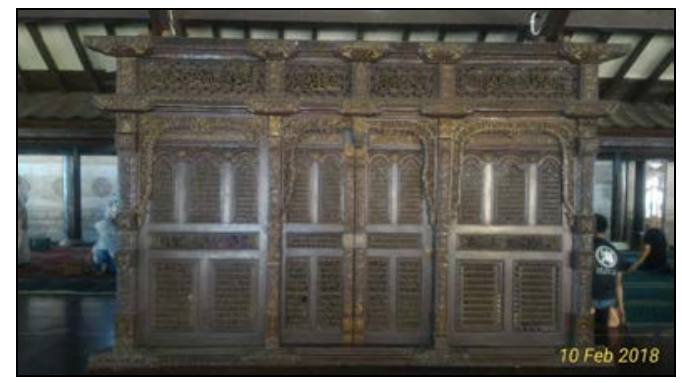

(b)

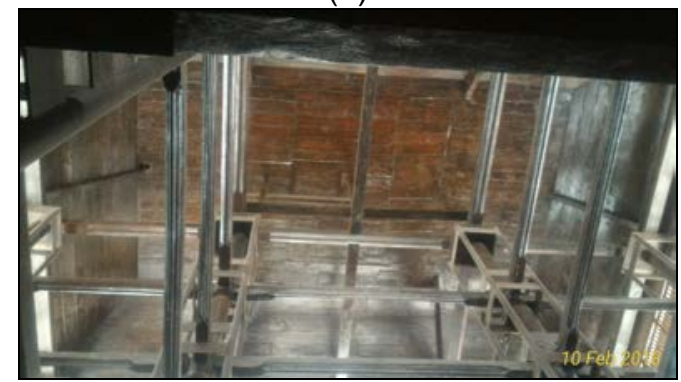

(c)

Gambar 3. Kondisi Faktual Masjid Sang Cipta Rasa Sumber: dokumentasi pribadi

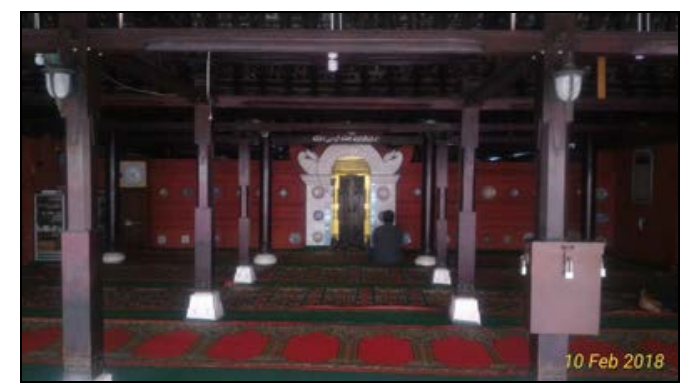

(a)

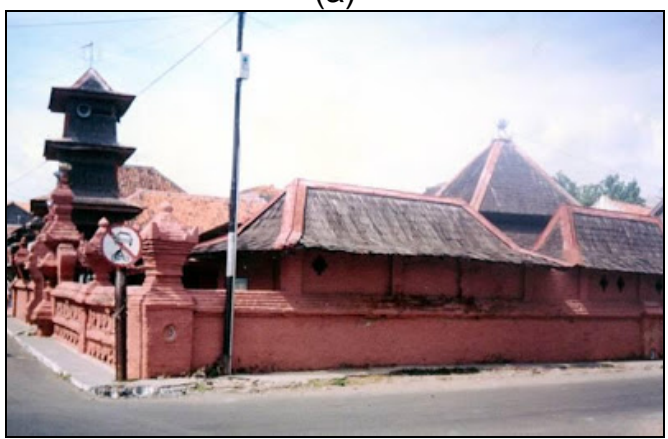

(b)

Gambar 4. Kondisi Faktual Masjid Merah Panjunan Sumber: dokumentasi pribadi dan http://penjagagaiba.blogspot.com/2013/07/masjid-merahpanjunan.html

Berdasarkan Tabel 4 diketahui bahwa Masjid Sang Cipta Rasa memenuhi $37.84 \%$ dari kesiapan sarana dan prasarana bangunan wisata, sedangkan Masjid Merah Panjunan hanya memenuhi $35.14 \%$ saja. Kedua masjid sebagai bangunan wisata tersebut bisa dikatakan masih kurang siap khususnya dalam aspek keselamatan dan kemudahan (minimnya fasilitas rambu dan marka (signage) serta fasilitas keselamatan seperti akses evakuasi dan perlengkapan P3K). Dalam lingkup pemeliharaan bangunan wisata yaitu aspek arsitektural, tata luar ruang dan housekeeping tidak dijalankan dengan baik 
karena bangunan wisata yang seharusnya menunjukkan keindahan dan estetika tidak terlihat pada kenyataannya. Gerbang dan pagar Masjid Sang Cipta Rasa ditumbuhi lumut sehinga tidak terlihat indah dan bersih serta bisa melapukkan batunya (lihat Gambar 3(a)). Oranamen ukiran kayu di kedua masjid tidak dibersihkan dan dipoles sehingga terlihat kusam dan tidak menarik (lihat Gambar 3(b) dan (c), serta 4(a)), lantai dan karpet yang berdebu, serta toilet yang kurang bersih dengan sistem sanitasi yang tidak memadai. Kedua masjid tidak ditunjang oleh ruang terbuka hijau, landscape dan hardscape yang memadai terutama Masjid Merah Panjunan.

Masjid Sang Cipta Rasa dan Masjid Merah Panjunan sebagai tujuan wisata (wisata religi) tidak memiliki area parkir umum yang cukup dan ramah bagi penyandang cacat, bahkan Masjid Merah Panjunan tidak memiliki area parkir sama sekali (lihat Gambar 4(b)). Selain itu, keduanya juga sulit untuk diakses menggunakan transportasi umum, terutama Masjid Merah Panjunan yang terletak di daerah pemukiman. Berdasarkan checklist pada Tabel 4 dan penjelasan yang disertai dengan dokumentasi konkret, tidak salah apabila dikatakan bahwa kedua masjid tersebut belum siap "dijual" sebagai bangunan wisata karena sarana dan prasarana yang belum memadai dan belum optimal, terutama dalam aspek keselamatan, kebersihan dan aksesibilitas.

\section{KESIMPULAN}

Kota Cirebon memiliki beberapa bangunan wisata, contohnya Masjid Sang Cipta Rasa dan Masjid Merah Panjunan, yang mampu menunjang city branding di bidang pariwisata. Namun, bangunan wisata tersebut belum layak dalam keandalan bangunan karena sarana dan prasarananya belum memadai dan belum oprimal, khususnya pada aspek keselamatan dan kebersihan. Oleh karena itu, dalam perspektif ilmu Teknik Sipil, bangunan-bangunan tersebut tidak dapat dikategorikan sebagai bangunan yang aman dan nyaman sebagai tempat wisata dan tidak memenuhi persyaratan teknis sebagai potensi city branding Kota Cirebon.

\section{SARAN}

Berdasarkan hasil analisa yang telah dilakukan, penelitian ini menyarankan beberapa hal sebagai berikut:

1.Dalam mempersiapkan sarana dan prasarana bangunan wisata secara optimal, diperlukan kerjasama dari pemerintah, pihak swasta selaku pengusaha jasa pariwisata, masyarakat kota Cirebon dan para wisatawan/pengunjung

2. Adanya penelitian lanjutan dengan topik misalnya: (a) kekuatan struktur bangunan wisata; (b) estimasi biaya pengoptimalan sarana dan prasarana bangunan wisata; serta (c) rekomendasi perbaikan struktur dan arsitektur bangunan wisata; untuk semakin memperkaya referensi dalam meningkatkan city branding kota Cirebon khususnya di bidang pariwisata (bangunan wisata)

3. Adanya tindak lanjut dan realisasi dari hasil penelitan

\section{UCAPAN TERIMA KASIH}

Ucapan terima kasih ditujukan khusus kepada Ibu Eli Jamilah Mihardja, Ph.D. dosen Program Studi IImu Komunikasi, yang telah memberikan kesempatan untuk ikut serta dan berperan aktif dalam penelitian, LPP Universitas Bakrie yang telah menyediakan dana untuk pelaksanaan penelitian, serta rekan-rekan dosen di Program Studi Teknik Sipil atas dukungan, arahan, dan koreksinya.

\section{REFERENSI}

Adriansyah, R. T. (2014). Estimasi Biaya Pemeliharaan Bangunan Berdasarkan Pedoman Pemeliharaan dan Perawatan Bangunan Gedung (PERMEN no.24/PRT/M/2008): Studi Kasus Bangunan Masjid Islamic Center Bangkinang. Jurnal Online Mahasiswa (JOM) Bidang Teknik dan Sains Vol.1 No.1, 1-16.

Anonim. (2018, Mei 5). Retrieved September 17, 2018, from majalah langitan website: http://majalahlangitan.com/masjid-agungsang-cipta-rasa-peninggalan-walisongo-dikota-cirebon

Dinnie, K. (2011). City Branding: Theory and Cases. London: Palgrave Macmillan.

Gaiba. (2013, Juli 17). Retrieved September 17, 2018, from penjaga gaiba blogspot website: http://penjagagaiba.blogspot.com/2013/07/ma sjid-merah-panjunan.html

Jannah, B., Arifin, Z., \& Kusumawati, A. (2014). Pengaruh City Branding dan City Image terhadap Keputusan Berkunjung Wisatawan ke Banyuwangi. Jurnal Administrasi Bisnis (JAB) Vol.17 No.1, 1-7.

Karim, M. Y., Pontoh, N. K., \& Putra, B. D. (2014). Potensi Kota Cirebon yang Mendukung Pembentukan City Branding. Jurnal Perencanaan Wilayah dan Kota A SAPPK Vol.1 No.1, 154-162.

Kavaratzis, M. (2004). From City Marketing to City Branding: Towards a Theoritical Framework for Developing City Brands. Place Branding Vol.1 No.1.

Kavaratzis, M., \& Ashworth. (2006). City Branding: An Effective Assertion of Identity or $A$ Transitory Marketing Trick. Oxford: Blackwell Publishing Ltd.

Nabarentcar. (2014, Agustus 19). city tour cirebon. Retrieved September 17, 2018, from nabarentcar website: http://www.nabarentcar.com/city-tour-cirebonsejarah-masjid-merah-panjunan/ 
Nursinggih, H. (2001). Kajian Komponen Penawaran dan Permintaan Wisata sebagai Penunjang Kepariwisataan Budaya Kota Cirebon. Semarang: Tesis - Universitas Diponegoro.

Republik Indonesia. (2002). UU No.28 Tahun 2002 tentang Bangunan Gedung. Jakarta.

Republik Indonesia. (2005). PP No.36 Tahun 2005 tentang Peraturan Pelaksanaan UU No.28 Tahun 2002. Jakarta.

Republik Indonesia. (2006). PERMEN PU No.29/PRT/M/2006 tentang Pedoman Persyaratan Teknis Bangunan. Jakarta.

Republik Indonesia. (2006). PERMEN PU No.30/PRT/M/2006 tentang Pedoman Teknis Fasilitas dan Aksesibilitas pada Bangunan Gedung dan Lingkungan. Jakarta.

Republik Indonesia. (2008). PERMEN PU No.24 Tahun 2008 tentang Pedoman Pemeliharaan dan Perawatan Bangunan. Jakarta.

Republik Indonesia. (2016). PERMEN Pariwisata No.14 Tahun 2016 tentang Pedoman Destinasi Pariwisata Berkelanjutan. Jakarta.

Romandhona, D. (2016). Pengelolaan, Partisipasi, Potensi dan City Branding sebagai Upaya Pengembangan Industri Pariwisata di Kota Surabaya. AntroUnairdotNet Vol.V No.3, 518533.

Sukmaraga, A. A., \& Nirwana, A. (2016). City Branding: Sebuah Tinjauan Metodologis dengan Pendekatan Elaboratif, Praktis dan Ilmiah. Journal of Art Design, Art Education and Culture Studies (JADECS) Vol.1 No.1.

Susilo, W. H. (2011). Observasi di Kota Cirebon: Suatu Potensi Pariwisata dengan Meningkatkan Keberadaan Heritage. Jakarta: DIKTI.

Wibawanto, S. (2015). Pendekatan Konseptual Place Marketing dan Place Branding dalam Destination Branding. Jurnal Fokus Bisnis Vol.14 No.2, 42-59.

Widodo, B., \& Setiansah, M. (2014). Strategi Pencitraan Kota (City Branding) Berbasis Kearifan Lokal (Studi Kasus di Kota Solo, Jawa Tengah dan Kabupaten Badung, Bali). Jurnal Komunikasi Profetik Vol.7 No.2, 33-44. 